\title{
Fulminant Liver Failure Associated with the Use of Black Cohosh
}

\author{
Josh Levitsky · Tyron A. Alli · James Wisecarver • \\ Michael F. Sorrell
}

Published online: 12 June 2007

(C) Springer Science+Business Media, LLC 2007

\section{Erratum to: Dig Dis Sci (2007) \\ DOI: 10.1007/s10620-005-2470-7}

After the article was published, it was brought to the authors' attention through legal documentation and testimony that the patient admitted to consuming alcohol and had been taking other medications at the time of her initial presentation of liver failure. From these records, she reported drinking no more than six glasses of wine per week. In addition, up until presentation, she was taking valacyclovir $500 \mathrm{mg}$ daily for herpes prophylaxis for 2 years, an occasional pseudoephedrine tablet, calcium carbonate $500 \mathrm{mg}$ three times daily, iron sulfate $325 \mathrm{mg}$ daily and ibuprofen up to three times weekly. She had been taking erythromycin tablets but discontinued those 3 months prior to presentation.

The authors regret the omission of this information from the original case report. While this new information is

The online version of the original article can be found under doi:10.1007/s10620-005-2470-7.

J. Levitsky · M. F. Sorrell

Department of Gastroenterology, University of Nebraska

Medical Center, Omaha, Nebraska, USA

T. A. Alli

Gastro-Intestinal Associates, P.C., Omaha, Nebraska, USA

J. Wisecarver

Departments of Pathology/Microbiology, University of Nebraska

Medical Center, Omaha, Nebraska, USA

\section{F. Sorrell ( $\square)$}

Section of Gastroenterology, University of Nebraska Medical

Center, 983285 Nebraska Medical Center Drive, Omaha,

Nebraska 68198-3285, USA

e-mail: msorrell@unmc.edu important to include as a correction to the history, it does not change the authors' clinical opinion as to the association between the patient's consumption of black cohosh and the development of liver failure. She was not consuming enough alcohol, pseudoephedrine, or ibuprofen to lead to the clinical presentation or pathologic appearance described in their report. Valacyclovir, a drug often given to liver transplant recipients for herpes and cytomegalovirus prophylaxis, has only been shown in one case report to be associated with hepatitis [1] and had been given at low doses without modification for 2 years prior to presentation. Finally, while there are clear reports of erythromycininduced hepatotoxicity, the patient had stopped this medication 3 months prior to presentation.

\section{Reference}

1. Renkes P, Trechot P, Blain H (1999) Valacyclovir-induced hepatitis. Acta Clin Belg 54:17-18 